\title{
Erratum to: Development and application of lateral flow test strip technology for detection of infectious agents and chemical contaminants: a review
}

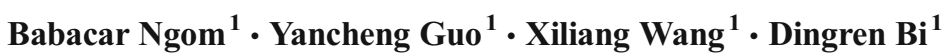

Received: 29 March 2016 / Accepted: 29 March 2016/Published online: 5 April 2016

(C) Springer-Verlag Berlin Heidelberg 2016

Erratum to: Anal Bioanal Chem

DOI 10.1007/s00216-010-3661-4

The authors would like to call the reader's attention to the fact that unfortunately Martina Blazkova's name was misspelled in three citations of the original publication.

The references should read:

14. Blazkova M, Koets M, Wichers JH, Amerongen AV, Fukal L, Rauch P (2009) Czech J Food Sci 27:S350-S353

26. Blazkova M, Koet M, Rauch P, Amerongen AV (2009) Eur Food Res Technol 229:867-874

134. Blazkova M, Mickova-Holubova B, Rauch P, Fukal L (2009) Biosens Bioelectron 25:753-758

The online version of the original article can be found at http://dx.doi.org/ 10.1007/s00216-010-3661-4.

\section{Xiliang Wang}

wx1070@163.com

$\triangle$ Dingren Bi

bidingren@mail.hzau.edu.cn

1 State Key Laboratory of Agricultural Microbiology, College of

Veterinary Medicine, Huazhong Agricultural University,

Wuhan 430070, China 